\title{
Interactive comment on "Sensitivity of
} instrumental line shape with respect to different optical attenuators and resulting error propagation into atmospheric trace gas retrievals" by

\section{Y. W. Sun et al.}

Y. W. Sun et al.

ywsun@aiofm.ac.cn

Received and published: 17 September 2016

Please check the supplement for the detailed response to comment\#1

Please also note the supplement to this comment:

http://www.atmos-meas-tech-discuss.net/amt-2016-1/amt-2016-1-AC1-

supplement.pdf 